Pre-print version: Soriano, C.R. \& Panaligan, J.H. (in press). 'Skill-Makers' in the Platform Economy: Transacting Digital

Labour. Digital Transactions in Asia (Athique, A. \& Baulch, Em, Eds). London \& New York: Routledge.

\title{
'Skill-Makers' in the Platform Economy: Transacting Digital Labour
}

Cheryll Ruth R. Soriano and Joy Hannah C. Panaligan

De La Salle University

The increasing global connectivity and the relative affordability of technology heralded the rise of online platform labour or digitally-mediated service work. Digital platform workers (also referred to as 'online freelancers' in this paper) engage in digitallymediated work through online labour platforms and microwork intermediaries such as Sama-source, CrowdFlower, Freelancer.com, and Upwork. In contrast to business process outsourcing such as call center work, digital labour platforms represent a new model as they allow business processes to be outsourced without the mediation of formal business process outsourcing (BPO) companies (Graham, Hjorth and Lehdonvirta 2017: 137). In these platforms, clients or buyers of work (mostly located in high-income countries) post jobs in these platforms and aspiring workers (mostly located in lowincome countries) bid on them directly (Wood et al. 2016:.1). The Philippines, the site of this study, is second to India in terms of the number of online platform workers actively involved in the market (Graham, Hjorth, and Lehdonvirta 2017: 142).This chapter focuses on the rise of 'skill-makers,' specialist coaches who attract and train platform workers into this labour market and the 'skill-making economy' which is playing a crucial role in the local popularity and viability of platform labour.

As a lens for analyzing digital transactions in the context of labour, the need for skillmakers and the very rise of the skill-making economy embodies the monetization of ambiguity underlying digital labour in the global South. Burdened by employment woes such as infrastructural immobility and low wages, countless Filipino professionals and even those who were once deemed as undesirables under local labour standards are found to be migrating to online platform labour in exchange for autonomy, spatial flexibility, and the possibility for higher earnings, etc. Government's optimism towards digital labour can be seen in parallel to Richard Florida's notion of the rise of the 'creative class', which was about this new group of socio-economic subjects who had jobs based on creativity and individual talent and who could usher cities into a new era of economic development and prosperity while addressing the unemployment gap (Florida, 2006). Valorized under the guise of creativity and flexibility, platform labour is seen as empowerment for Filipino workers: it provides them with new work opportunities to earn dollars, it gives them entry into the 'global workplace', and facilitates a flexible work arrangement that allows them to overcome the challenges of daily commute while spending valuable time with their families at home. However, these optimistic narratives are challenged by the pernicious conditions that digital workers face: from exploitation to isolation to the colonization of personal space (for example, Arvidsson et al. 2010, Fuchs 
and Sevignani 2013, Gandini 2015, Gill and Pratt, 2008,Gregg, 2011, Hesmondhalgh and Baker 2010, Irani 2013, Peck 2005, Van Doorn 2017).

Digital platform labour may be considered part of the wider category of 'non-standard employment' (Kalleberg 2009). The nature of work would characterize them as among the 'precariat,' underscored by 'distinctive relations of production' that involve so-called 'flexible' labour contracts, temporary jobs, labour as casuals, part- timers...' and 'distinctive relations of distribution' characterized by the absence of non-wage benefits such as health coverage, paid leave, or retrenchment benefits (Standing, 2014: 969-970). As such, they are less likely to be able to access community support systems or state benefits. Amidst celebrations of flexibility, those in the precariat have 'no secure occupational identity' and 'no occupational narrative they can give to their lives' as a result of constant movement across available jobs that would not allow full use of their educational qualifications (Standing 2014: 969). Recent works on digital labour have also talked about 'flexible exploitation,' which pertains to the double-edged nature that affords people new ways of working but also brings with it new kinds of precariousness (Gandini 2016, Wood et. al. 2016, Graham, et al. 2017). These difficult conditions are not unknown to local platform workers. Yet, although these studies do the important work of training their lens on the problematic realities of digital labour, they at times insufficiently address how local conditions, histories, and dynamics allow workers to rationalize, negotiate, and even challenge these unfavorable work conditions (Hesmondhalgh and Baker 2010, Kennedy 2011).

Skill-makers emerge as an important labour category as they help platform workers reconcile the ambiguous condition of digital platform labour. Skill-makers play a role in ushering aspiring platform workers towards the vision of what they can be in this digital labour environment and train them with 'practical strategies' to achieve 'success'. At the same time, 'skill-makers' are also very well aware of the precarity of platform labour. Most of them current or former digital platform workers too but have achieved some level of success, they know the ambiguity of shifting into platform labour from regular full-time employment, the pernicious and unfair conditions yielded by the platforms' design (i.e. labour arbitrage, the platform's socio-technical system of rating workers), and have been exposed to the difficulties of working with foreign clients. In short, they rise as an 'elite group' of workers because they capitalize on their experiences of and exposure to the challenges of digital labour and translate these as positive narratives and skills that they can monetize as training packages. Despite government pronouncements promoting digital labour as a crucial solution to unemployment, mechanisms for supporting workers engaged in labour platforms are absent. For labour migration, several private and public institutions have been set up to help workers aspiring to migrate overseas for jobs in terms of employment seeking, expectation-setting, salary identification, taxation, or welfare protection. For BPO-related jobs such as call center work, foreign companies operating in the country have institutionalized recruitment and employment mechanisms (Kleibert 2015). By contrast, aspiring workers bid for jobs in labour platforms directly and many workers learn the ropes through years of experience and by taking on several gigs from different platforms. 
For newcomers, platform labour is confusing: not only is the process of engaging in platform labour fully mediated, but one also needs to discern legitimate platforms and legitimate clients from scams, present oneself and one's skills in a compelling manner and in a foreign language, and manage client's demands. For those transitioning from full time employment (usually from call centers), to full time freelancing through platform labour, workers are often wary about security or seasonality of work, the availability of non-salary benefits, or whether there are mechanisms for redress if clients end up not willing to pay for completed tasks. Some workers entering the digital platform economy may not have educational or professional training for jobs that they are eyeing but believe that getting employment is possible if they can get the right 'recipe' for success - again as marketed by skill-makers. Some aspiring workers, situated across the archipelago, but without university degrees, seek new skills or ways to package what they know in order to realize the promises of digital platforms. Strategic pricing is also a common source of ambiguity given the nature of bidding for jobs embedded in the digital labour platform design. With many workers also ending-up being victimized by scammers and abusive clients, some of the workers aiming to tap into the rose-tinted promises of this industry require the guidance of people for navigating its complex environment. This chapter will show that it is in presenting their capacity to bridge the difficult realities of platform labour with the aspirational narratives that these 'skill-makers' create value for themselves and their work. As such, monetizing ambiguity as embedded within a specific context of Philippine labour, economy and society and digital platform labour, is at the heart of the transactional nature of this emerging labour category.

Arvidsson claims that in the digital economy, value is increasingly crystallized around the 'progressive mediatization of the social' and 'accompanying new forms of social organization' (2009: 13-14, 27). Arvidsson terms this as philia, a form of social capital which arises from one's ability to form affective bonds (ibid: 20). As 'the aggregate of the actual or potential resources which are linked to possession of a durable network of more or less institutionalized relationships of mutual acquaintance and recognition,' social capital can be enacted in groups or communities which provides each of its members with the backing of the collectivity-owned capital, or a 'credential '(Bourdieu, 1986: 51). In the Philippines, skill-makers have initiated 'online communities' of support (i.e. Facebook groups) that serve as active sites for skill making while playing an important function for geographically dispersed workers who need to grapple with the ambiguous condition of digital platform labour. These Facebook communities for online Filipino freelancers seek to host expressions of belonging, support and mutual kindness, as well as sharing of skills, tips and opportunities among Filipino digital platform workers - abstracted social formations imagined through the shared experience of mediation and communication. However, also following the more recent critiques of online communities as sites of commercial culture that serve as an 'audience base' for various marketing purposes, we explore the role of these communities through shared experiences of platform work while at the same time serving the purpose for skill-making and maintaining an audience of subscribers or potential clients. Skill-makers take advantage of these sites for enacting multiple kinds of transactions - transactions between skill-makers and platform workers, hosting transactions among platform workers, and transactions between skill-makers and digital labour platforms (Athique 2013: 62). In this chapter, we ask: how do skill-makers 
monetize 'philia' or the formation of social bonds and relationships by helping workers reconcile the ambiguities of digital platform labour? What are the communicative strategies enacted by skill-makers in these 'communities' that allow them to enact multiple transactions and sustain their value in this digital economy?

\section{Systematic Production of Filipinos as 'World-Class Service Workers'}

The Philippine government champions digital labour as a way to overcome the various employment woes faced by countless Filipino professionals across age groups and educational background. The 'globalization' of business services propelled by the development of information and communication technology (ICT) allowed for the relocation of voice-based call centres and other back-office processes from the Global North to the Global South. Ranked as having the worst unemployment rates in Asia but with a large English-proficient population, the Philippines has become one of the prime sites of BPO work (Abara and Heo 2013, Errighi, Khatiwada and Bodwell 2016). However, the precarious conditions of BPO work, such as constant night shifts and sleep deprivation, highly stressful work environment, working in cramped cubicles for hours, lack of professional advancement, along with the difficulties of daily commute, has compelled some workers to explore alternatives (Errighi, Bodwell and Khatiwada 2016, Fabros 2016). The government sees platform labour as a complement to other forms of BPO work, an alternative to overseas labour migration, a catalyst for urban and rural development, and an attractive option for young graduates. The Philippine government has used labour brokerage as one of its neoliberal strategies to bring in much-needed foreign currency inflows (Rodriguez 2010). In the last decades, it has continually touted the mantra of Filipinos being 'world class service workers and 'modern heroes,' helping drive labour export despite the precariousness associated with such work (Parreñas 2001). From foreign domestic labour to call center labour and now to digital platform labourFilipinos aim for work that match their distinct traits as the top service workers of the world despite the many exploitative conditions accompanying this distinction.

The notion of the Philippines as a nation systematically training and exporting service workers for the global market has been predominantly constructed as a 'natural global order of things' that Filipinos ought to take advantage of (Fabros 2016). Platform labour is envisioned to address rural development and unemployment in the country, but also as an alternative to foreign labour migration. The labels of 'modern heroes' and 'world-class workers' that have been previously attributed to overseas Filipino workers are being gradually conferred on online freelance workers too. They are now labelled as the OFW 2.0, no longer the 'Overseas Filipino Worker' but the 'Online Freelance Worker'. Through digital labour, one still earns dollars and performs as a 'global worker,' only this time without having to be away from home. Providing a boost to the Philippine economy, this, however, constructs the Filipino as a global commodity and a colonized subject. In economic terms, the salaries of digital workers place them within the country's middle classes whose monthly income ranges from PHP 15,780.00 (approx. USD 308.00) to PHP 157,350.00 (approx. USD 3071.00) (Hau,2017; Soriano \& Cabanes, forthcoming), with most earnings exceeding the local minimum wage of P512/day or P15,360/month (approx USD288). Further, local news occasionally highlights 'success' stories of online 
freelance workers earning millions of pesos in a year, serving as encouragement to workers on the viability of platform labour (see for example, Garcia 2014). However, if compared to the so-called 'new middle class', who are 'professional and technical workers on the one hand, and wage- and salary-earning administrators, executives, and managers on the other hand', platform workers may be seen less favorably. As the labour is primarily comprised of off-shored low-skilled occupations being taken up by the country's highly educated and young workforce, platform labour in the Philippines is distinctly ambiguous because of the jobs mismatch that predominate this kind of work, which is often characterized as 'low prestige' in the Global North (Bolton 2010, Kimura 2003: 265, Magtibay-Ramos et al. 2007, Roberts 2016, Rodolfo 2005, Soriano and Cabanes, forthcoming).

Similar to other jobs in the country's business process outsourcing (BPO) industry such as call centers, transcription, or content moderation, most of the jobs under platform labour are believed to involve 'a narrow job description and offer only limited opportunities for acquisition of knowledge and skills replicable in other professions' and, crucially, often have poor 'longer-term employment prospects' (Beerepoot and Hendriks, 2013: 824). Yet, the earnings obtained by workers from these jobs allow them significant purchasing power in the Philippine context and maintain 'middle-class lifestyles' such as buying a car, paying for a condominium unit, sending children to school, or visiting cafes which characterize contemporary middle class life (Fabros 2016, Soriano and Cabanes, forthcoming, Tadiar 2004). Further, Filipino professionals are also migrating to online platform labour in exchange for autonomy and spatial flexibility. Digital labour, although understood to be facilitating a precarious form of labour, is actually fulfilling for workers in comparison to previous work conditions that tied them to experiences of constraint and control (Soriano and Cabanes, forthcoming). These include the lack of secure employment opportunities and the growing difficulties of commuting from one's home to the workplace due to worsening traffic conditions. At the core of flexibility are the neoliberal ideologies of 'individual entrepreneurial initiative' or 'individual selfrealization'-middle class aspirations as well-- that compel the workers to get around the controls of corporate institutions and the inefficiencies of public institutions (Gandini, 2016, van Doorn, 2017: 900). Skill-makers promote aspirations of a flexible working environment and 'unlimited opportunities', while training workers for the 'discipline' needed in order to succeed. In doing so, however, it is possible, as Peck has argued, that skill-makers promote the dangers of a narrative which 'glorifies and naturalizes the contracted-out, 'free-agent' economy without regard for the exploitative tendencies of a highly flexible working environment that arise from this economic system (2005: 756).

\section{Microcelebrities and Communicative Strategies for Influence Building}

Rapid advancements in technology facilitated contemporary shifts on who can become 'celebrities' and obtain a following or influence (Hearn 2015). The concept 'microcelebrity' pertains to how people used online tools in 'amping up their popularity over the web using technologies like videos, blogs and social networking sites,' earning them fame and prominence just like mass media celebrities (Senft 2013: 25). These practices are pursued in light of the so-called 'attention economy' where value is 
attributed based on the capacity to attract attention in a media-saturated and informationrich world. These include niche-like celebrities thriving in multiple environments such as fashion, food, entertainment and eventually earning followers by engaging a set of practices to boost popularity and maintain influence (Marwick 2015). But how do microcelebrities develop influence? Marwick suggests they do so through 'selfpresentation techniques,' micro-celebrities create a brand, a 'public persona to be consumed by others and engage the strategic use of 'intimacies' to attract followers (Marwick 2015: 1). While microcelebrities may be actively engaged in 'self-expression', this also simultaneously works as an economic activity and serves as a way to monetize the self in the digital world.

Micro-celebrities may amass a smaller scale of followers compared to celebrities, but the 'strategies of microcelebrity can forge a loyal following' on any social media platform (Khamis, Ang and Welling 2016: 12). As Hearn and Schoenhoff explain, social media works to generate a form of 'celebrity capital' by cultivating as much attention as possible and crafting an authentic and relatable 'personal brand' via social networks, which can subsequently be used by companies and advertisers for consumer outreach' (2016: 194). The notion of self-branding further implies that a microcelebrity needs to differentiate oneself from the rest by creating a persona, a character or role created to project one's image in the content or product they create, and eventually display influence over people (Abidin 2017). They must also specialize the self, since their persona must pertain to the area of expertise the online influencer would like to be associated or known for. This labour specialisation of a persona illustrates how advertising shifts from mass media to marketing 'personal sensations' through the use of a personal touch to establish a connection with the audience and target emotions (Malefyt and Morais 2012: 62).

The concept of communicative intimacy is crucial in the reputation building process of micro-celebrities because it emphasizes the relationship between influencers and followers--or how influencers 'intentionally used digital media to craft, convey, (and) sustain intimacies with their followers' (Abidin 2015: 8). By enacting communicative intimacy, followers can easily relate to influencers because the interactions they have with them seem 'personal' or 'direct' through the recreation of 'intimate exchanges' (Abidin 2015). Abidin identified four (4) types of intimacies appropriated by influencers: commercial, interactive, reciprocal, and disclosive. For instance, commercial intimacies describe the recreation of an 'intimate exchange' between the influencer and followers for commercial interest (ibid: 5). This illusion of intimacy works 'as long as followers (who 'may or may not be critically aware of these') feel familiar, close, and emotionally attached to influencers' (ibid: 5). Commercial intimacy includes how an influencer can earn views and hits from emotional posts and personal stories. Interactive intimacy, on the other hand, is an 'extensive integration of face-to-face meet-ups with followers' which can range from informal events organized by influencers or brand sponsorships (ibid: 6). The third is reciprocal intimacy, which refers to forms of facilitating mutual acknowledgment and appreciation between influencers and their followers in the form of shout-outs, retweets, comments, and likes (ibid: 7). 
Finally, developed in the context of lifestyle influencers, disclosive intimacies include 'behind-the-scenes' portrayals that allow followers to gain access 'to the private, usually inaccessible aspects of influencers' (p.8). Such personal posts have the capacity to boost attention and craft a notion of authenticity and relatability for their audiences. The enactment of communicative intimacies is strategic, allowing microcelebrities to increase influence and maintain a 'perception of interconnectedness' between them and their followers (Abidin, 2015: 1). Thus, the concept of microcelebrity and social media influencers is largely understood to operate in niche-like environments such as fashion, entertainment, blog, travel and the like, and often in the context of affluent societies. There is a research gap in understanding the influence-building process wielded by skillmakers despite their growing influence as major drivers of digital labour in the locale and their role in crafting the imaginaries of workers embracing this form of work.

\section{Skill-Making in the Platform Economy}

Through an ethnographic inquiry of online freelance work in the Philippines, we examined the conditions that allowed digital workers to rise as skill-makers, the function of 'skill-making' in the digital platform economy, and looked into communicative strategies that they engage. Programs and services offered by the skill-makers range from 'how to begin as an online freelancer', 'how to sell one's skills', coaching on specific skills (i.e. website development, social media management, web design, or virtual assistance), or advise on how to make successful investments of their earnings. Some of these are shared for free via their websites or Facebook communities but most of the materials are packaged as training programs or as books for purchase. The cost of a course can range from $\mathrm{P} 3,000$ (US\$55) to P15,000 (US\$300). Based on an interview with a coach/influencer, a beginner course on how to become a freelancer costs P5,000 (US\$100). Although prohibitive for a regular platform worker, some of them took such courses with the promise of success, made visible through a constant display of association, which students of whose coach have become 'successful' as well as of evidence of material success shared in online communities.

We hypothesised that skill-makers cascade imaginaries of success and mobility to their subscribers while also establishing 'norms of success' for platform workers. In presenting our findings, this section discusses the role of skill-makers and the communicative strategies that they engage to: a) convey authenticity and relatability, b) negotiate visibility and algorithmic influence, c) maintain reciprocity and responsiveness, and d) engage in selective disclosure -- all of which allow them to maintain online communities of subscribers where they create aspirational emulation and form affective bonds (philia) for enacting multiple transactions.

\section{Articulating expertise and persona}

Skill-makers curate their 'brand' by articulating expertise and the capacity to build skills in a specific field. As articulated by one skill-maker, 'In freelancing, it's the knowledge and expertise that the audience look for...one becomes an influencer if they look up to 
you because of the expertise that you have that can help them build the skills they need to succeed' (interview, Ginnie, 37, female). Digital workers seek for ways to improve their skills and how they can market these and skill-makers make sure that they highlight the specific value that they can contribute. To do this, skill-makers assert their expertisewhether in social media management, podcasting, video production, or virtual assistance. This expertise also needs to be articulated consistently. An SEO coach explains:

If you want to be known for something, you have to be able to always deliver content on a topic. It should be on a regular, consistent basis so people will get to know you like that person, 'that video guy' or that SEO coach and then they will start to like you and because you give value. Over time they will start to trust you because they can hear that you're helping people with this and doing something for that. There is nothing that you can get instantly...you have to be consistent with your content, that's the thing that people will look for. If you want to grow your influence because once they see that you are regularly posting something, they will be able to look forward to a specific thing that you serve... It's your fault if you're not consistent you're not giving your audience a chance to follow you properly if you're not consistent (interview, Andrew, male)

As explained by one skill-maker, one can establish authority by 'start(ing) with the problem and issue and then provide solutions' (interview, Richard, male). One example is coaching about 'working from home'. In the context of online freelancing, most are attracted to 'working from home' but often unfamiliar about the complexity of managing the overlapping environments of home/family and work. Although seemingly trivial, there are apparently a multitude of issues encountered by online freelance workers who work from home: establishing a quiet and conducive work environment, managing time and work hours, managing client expectations, or being able to address client expectations while caring for the family. All these are provided in targeted coaching programs and strategies, such as the 'Work from Home Roadmap', which essentially prescribe norms and protocols of managing the work-from-home environment. Another strategy is the curation of a 'persona' by which to establish one's authority and expertise. An online influencer usually takes into consideration the persona they want to project to differentiate one's content from other similar content offered by other skill-makers. The choice of persona is attached to a specific approach that influencers employ to craft an impression of relatability among their followers. As a blogger/ mom/ entrepreneur and brand ambassador shared (interview, Ginnie, 37):

In my blog_ _ I basically know the customer that I want to talk to...All of the topics that I create (are) aligned with the particular persona I have in mind. I created (this) in my mind as a mom/entrepreneur persona. There are a lot of mommy bloggers but you have to think what makes you stand out. I think my site is known for business related or entrepreneurship topics. I want to communicate that even if you're already a mom you can still set up a business. For the Manila workshop it's a similar strategy we have different personas we have in mind. We split it into different series, so in each (part of the) series 
there is a persona that the audience needs and we (already) have someone in mind if the topic is about freelance, entrepreneurial and professional.

In the above, Ginnie explains that when she creates content, she has a persona in mind and it also serves as a guide for programming future posts or coaching sessions. This persona can also describe the area of expertise a skill-maker would like to be associated or known for, for example, 'My whole thing is I want people to see, understand and know that I'm always for marketing, like that's the one I want people to know. I'm an expert at social media marketing, expert in branding, personal branding and that I always give value. Marketing, (how to) hustle, personal branding, and entrepreneurship' (interview, Emmanuel, 25, male).

\section{Community-building}

Community-building serves as an important anchor for the communicative strategies enacted by skill-makers (Williams 2016). Once a brand of expertise or persona is established, a skill-maker begins to accumulate a following. Williams identified the concept of a 'micro-community,' an initial community within the influencer economy that skill-makers develop once they accumulate followers (2016: 169). Most commonly, skill-makers attract a following through face-to-face coaching sessions (this may be given for free while some require payment), beginning with as small as ten to fifteen aspiring freelancers. As they start earning a name, skill-makers would be invited to speak during online freelancing events, and there would be one or two in different locations in the country every month. These allow the skill-maker to develop a network of trainees, a micro-community, yet even when the trainees have achieved some form of independence or success, they still lovingly label themselves as 'coached by' a particular skill-maker. All our skill-maker informants emphasized the importance of online communities to maintain their network of trainees with possibilities of growing their number:

For freelancing it's very important for us to build a community like this. Even if its virtual, even if you can only see them online, you still get to be with them. And also it's very hard because there is no pattern, you don't know when you will encounter scammer clients. Sometimes (we have experience that) the client would run away, there are no traces and, they could not pay the freelancer. So if you are just someone and no one gets to help you, it's very easy to be scammed, so that's the reason why the community is really important so we can also guide the newbies.... We can help them in their career (interview, Clara, female).

Moreover, the influencers also recognize the community as the fastest way to grow one's brand organically because it allows the audience to join in the conversation and share content.

(The online community) it's important, it's one of the fastest ways to grow your personal brand as an online businessman or as an entrepreneur. I mean it's important 'cause people naturally want to be part of the communities and 
people gravitate towards that sense of togetherness, they want to belong to a certain group. They also post things that matter to other freelancers, such as a photo of their work space or scammer clients they encounter. They resonate with the value of stuff that we talk about and then share their own experiences (interview, Emmanuel, male).

The community enables the recognition of the skill-maker's brand or prominence. Once the recognition is earned this would further develop into richer connections further developed in casual meetups, organized team-building events, and online interactions. The community has a particular value for freelancers who often work from home, mostly in isolation, and therefore functions as a support group for skill-makers and freelancers and which the skill-makers knowingly capitalize on:

I meet with freelancers face to face, and I couldn't find a group who was doing it at that time so, that's why I started Meetup.com, and then I was surprised that the first (event) we had 30 attendees so I started doing more meetups. I've been doing it for the past 4 years and that's how I really wanted to meet freelancers face to face knowing that they are also online most of the time. I know that they also want a break from time to time and to be part of a community and that's what I'm going after-- to build the community slowly both online and through the meetups (interview, Melvin, 37, male).

Skill-makers organize events such as informal meetups, workshops, courses, conferences, talks, webinars and even promotions. Online interactions also work as documentation of offline meetups. Skill-makers thus play the role of a bridge for freelancers to convene online and offline.

\section{Relatability and authentic communication}

Community building is mobilized by communicating authenticity and relatability. Authenticity as a construct is quite hard to pin down, 'authenticity can be described the same way- you know it when you see it, and you can't fake it' (Williams 2016: 136). Two lessons identified by Williams served as a guide to examine the construct of authenticity in the online freelance community: the first is about finding an authentic self, and second is to divorce oneself from an agenda and find one's authentic voice (2016: 127). The first lesson illustrates how the audience or readers within the online freelance community gravitate to the message that is rooted from personal experience and struggles. Skillmakers value authentic communication because it is linked to the position they earned in their community. For example, in one of the interviews, Clara, a skill-maker, notes that it is not always necessary to have a content plan or predefined structure, 'random posts' and 'posts from the heart' are more valued because these appear 'more authentic'. Furthermore, authentic communication implies an attempt to balance the potential of monetary gains and conveying one's genuine intent to help, as Emmanuel explains, 'What people love about me is being genuine and being authentic, I'm not trying to make money every single time like some people say that I could monetize my audience so much and that I could make so much money from the people who follow me' (interview, Emmanuel, 
male). Of course, Emmanuel has also gained financially from the courses he offers, and the availability of free courses serve an important purpose of attracting workers and showing a proof of concept.

According to our informants, people eventually know if a skill-maker's posts are driven by personal agenda and the workers get turned off by this. For instance, although an influencer can earn from advertisements in their web pages, engaging too much in sponsored posts can backfire and drive followers away:

What brings about engagement is mostly authenticity. I noticed that when I post something personal, emotional or like share about my daily struggles, it would typically earn more reactions and engagements compared to a sponsored post. I made a mistake last year because my engagement decreased and I noticed that there are a lot of sponsored posts. Sometimes it's not about getting brands to back you up but mostly you still have to post something from the heart, something that you created and it reflects what you believe and think (interview, Ginnie, 37, female).

One would see from the quote above that beyond the transaction of offering skills to aspiring workers, skill-makers are also able to monetize these transactions, including exchanges among the followers in these communities, through sponsored posts and advertisements. However, this particular transaction is less overt and needs to be managed by the skill-maker well to maintain an appearance of authenticity. Authenticity supports and creates credibility in the content they produce and brings them closer to their communities while helping attract new followers. It appears that skill-makers would often provide value first before they seek to monetize this value.

\section{Responsiveness and reciprocity}

Skill-makers engage responsiveness and reciprocity once they build a community. They acknowledge and appreciate their audience's response to their content and, knowing their position as experts, they aim to address inquiries attentively. Some coaches run several accounts to maintain contact to their followers: 'Well, they reach me on Facebook sometimes they would comment on my blog, YouTube channel, and Instagram. I regularly answer them in the channels that they message me in' (interview, Ginnie). Here, a coach offers some examples of how skill-makers mobilize responsiveness and reciprocal intimacy:

Directly, they message me, and I message back. If they comment I do my best to reply to everyone, every single one. I mean it's hard and I try, I don't get to do this all the time, though I do my best. I randomly reach out to people also. The thing that I do sometimes I sent voice notes to people they appreciate it a lot. It's an extra effort, extra layer for me to send voice notes sometimes video, video replies and they appreciate that kind of thing... I just want to give people something of course they have to show that they earned it right (interview, Emmanuel, male). 
Responsiveness and reciprocity also manifest in terms of how a skill-maker' gives back' to their followers as a way to acknowledge their support. This can range from featuring mentees who have achieved some success (usually done through video interviews published through Facebook Live in their micro-communities), posting comments of encouragement, to giving out access to training, free books, or free show tickets. As a transaction, it would appear that when a platform worker subscribes to a training program or coaching session, he /she also benefits from a multitude of other 'gifts.'

\section{Calibrated visibility and algorithmic influence}

The expectation of being present all the time and obtaining a substantial following through online communities emerged as recurring themes throughout our interviews. These allow influencers to build their brand, earn credibility and serve as a way to earn their subscribers' trust but it also implies that influencers pay close attention to the accumulation of support and the quantification of their influence. The relationship between skill-makers and followers cannot be built on impressions alone, people establish trust through constant visibility. Yet, our interviews support the idea that being consistent and visible in the community should be calibrated, it does not paint a good picture when a skill-maker is only visible at times that they need to promote or sell products and services. Here, 'calibrated visibility' is a construct inspired by Abidin's notion of 'constancy,' or the appearance of online availability $24 / 7$ as a strategy microcelebrities enact to achieve interconnectedness (2013: 4). In the digital platform labour community, however, calibrated visibility implies the constant production of valuable content, while simultaneously allowing community members to engage organically such that skill-makers do not dominate the conversation and avoid the impression of merely taking advantage of the community. To know what works, digital labour influencers also carefully study the pattern of interaction of their community-members:

I've been focusing on sending at 4 pm. It's just so happened (that) I saw a good consistent interaction during that time. It's like piggy-banking on the habits of people. It creates the habit for people to anticipate your content... So, I think it's good if you can integrate yourself in their habits because it's hard to gain attention now. It's the currency of the digital age. If you can be there consistently, I noticed some other marketers, they would only email if there is a promotion, if there is a launch, so sometimes people will have an idea that they will only see content if there is promotion. But if you're there, day in and day out, even after promoting something. There is a sense of reliability that you will not just be visible when you (need to) promote (interview, Mark, male).

Calibrated visibility is vital because it is construed by the online freelancing community as a reflection of commitment. It is evident that there are common communication strategies that online influencers share such as having a Facebook page, email list, courses, webinars, blog articles and the like that allow them to convey an active relationship with their followers. 


\section{Selective disclosure and aspirational emulation}

Recently I came from Bacolod for a friend's wedding... I shared a picture of me there, and it's like a personal look in my life. And also, since I sent that email on Valentine's day, in the PS part, I included the message I gave to my friend. So it's more about marriage tips, it's mixing up some personal details and the actual marketing tip, so there is a bonus like a personal (insight about), love since it's Valentine's day (interview, Mark, male).

Considered as figures of authority, workers are used to seeing professional advice from skill-makers. Inserting a personal story in between professional coaching appears to be a powerful attention grabber, as this creates an imaginary of intimacy between the influencers and their followers, akin to the concept of 'disclosive intimacy' (Abidin 2015). This communicative strategy is suitable to the nature of social media as a space for candid interaction while enacting a sense of 'relatability'. As one worker shared in a focus group discussion: 'His posts makes me think, 'oh he is just like us' (interview, freelance worker, female, 26). Yet, although a slice of the personal is revealed, the focus is on the value of content they provide, looped within personal stories of hardship and success that followers would find relatable. Skill-makers engage 'winning stories,' where they share their work history and story of success. In turn, freelancers also post what they have achieved, again presenting an image of possibility, an achievable success for aspiring freelancers that can be emulated:

They love the inspirational stuff, if you create or share a story about your struggles and how you overcame it, that works a lot especially if it's portrayed in story form, a long story form, text type. They love that stuff, that is how you engage. If you can show them, there is a way to achieve things despite all the odds, that works the best. Again it's either you can educate and inspire. If you can educate them in such a way that it's not boring and in an entertaining way that's also good. If you can educate, entertain, and inspire them that's perfect (interview, Arvin, male).

Inspirational posts also attract others in the community to share their own experience and reveal their success stories to inspire beginners, thereby creating a greater sense of authenticity as these become a collaboration between the skill-maker and their followers - a picture of real-life stories of success and overcoming difficulty. This works to establish the skill-maker's authority and believability within a growing network of followers and community members.

\section{Transacting the Ambiguities of Digital Labour}

Digital labour in the Philippines has created opportunities for skill-makers: a labour elite that has become successful and transitioned into becoming online freelancing coaches. These skill-makers cascade imaginaries of success and mobility to their subscribers that also create aspirations for the workers who now have to compete with thousands of new aspirants. By building their respective communities, skill-makers establish their brand of 
expertise and authority and at the same time enact a range of communicative strategies underscored by authentic communication, calibrated visibility, reciprocity, algorithmic influence, and selective disclosure that all create aspirational emulation amongst their followers. In turn, digital workers also establish skills and social capital by being attached to the skill-maker and gaining a community of support crucial in an ambiguous labour environment. Invested with the expectation of future returns that are appropriable and convertible, skill-makers establish communities with which they offer a diverse range of training and coaching resources that allow them to build reputation and trust. In turn, digital workers also capitalize on their being coached.This surfaces transactions underlying the relationship between the skill-maker and digital platform workers: skillmakers monetize the value of helping workers solve the ambiguity of the digital platform environment, in turn, workers see the need for skill-makers due to the perceived value that they can offer for helping them advance in the digital labour economy.

Yet it appears that skill-making is not really just about training platform workers to develop new skills needed to thrive in the digital platform economy, although much of the work falls into this. To maintain influence in this environment, skill-makers also perform multiple kinds of work: creating and sustaining communities, producing and exchanging content in these communities, being continually responsive to queries, negotiating visibility and sharing aspects of one's personal life, among others. Skillmakers also perform unpaid labour for digital platforms. As key movers inspiring local workers to take up platform labour to training them as entrants to this industry, skillmakers essentially function as recruiters for digital platforms by making the ambiguous digital platform environment less complex for local workers--a total gain for digital labour platforms. Indirectly, they also serve as promoters of the government's vision of promoting Filipinos as 'world class workers' and in some way, supports it's goal of reducing unemployment. Recently, we found that government has begun to partner with a prominent skill-maker for promoting online freelancing and delivering training programs for aspiring digital workers in rural communities under government's 'Rural Impact Sourcing Program.' This is a new development that may further expand the role of skillmakers, the reach of digital platform labour, and the transactions that may be embedded within. One of the challenges is to build collective representation for those espousing the values of work outside the norms of labour, and which can help workers manage some of the underlying ambiguities (ibid: 978). With little tangible support, skill-makers work to manage the ambiguities of digital platform labour through the creation of protocols and guidelines to help workers bargain for better rates, negotiate job scope, avoid scammers, or find labour platforms that provide better deals.

The very idea of having to invest in 'skill-making' programs in order to become successful creates norms and lofty standards that further creates asymmetries that disadvantage certain workers while benefiting others. A skill-maker takes the position of one who has obtained success, as one who has expertise but continually expands skills, one who has the capacity to discern good clients, one who can navigate a global workplace, one who invests earnings in the right places, one who can successfully navigate a 'work-at-home' environment, one who presents an appearance of sincerity while being able to monetize this influence--all of which allow them to gain the trust of 
their followers. Nonetheless, skill-makers are digital workers too. Although they are admired and obtain a significant following, they take the stance of being 'one of them.' Skill-makers, a growing league of influencers in the local digital labour economy, strategize their narratives of success and promote recipes for success in digital platform labour. They create the notion that anyone can be like them, successful, entrepreneurial, well-networked, and 'contributing to bigger social good'. However, the reality is that the skills and assets that allow them to flexibly navigate across digital labour spaces and opportunities to negotiate with clients may not be as easy to come by for others, who will remain in the general labour pool. Nonetheless, the relationships between skills makers, as mentors and advocates, and the flexible pool of precarious labour creates a series of critical transactions around opportunity in the platform economy, thereby establishing norms and protocols that both mitigate and perpetuate the precarity of digital platform workers. These transactions between different categories of labour deserve further research if we are to properly understand the consolidation of the platform economy. 


\section{References}

Abara, Anna Charmaine and Heo, Yoon (2013) 'Resilience and Recovery: The Philippine IT-BPO Industry During the Global Crisis', International Area Studies Review, 16 (2): 160-183.

Abidin, Crystal (2013) 'Cyber-Bffs*: Assessing Women's 'Perceived Interconnectedness' In Singapore's Commercial Lifestyle Blog Industry *Best Friends Forever',Global Media Journal: Australian Edition, 7(1): 1-20.

Abidin, Crystal(2015)'Communicative Intimacies: Influencers and Perceived Connectedness', Ada: A Journal of Gender, New Media, and Technology, 8: 1-16.

Abidin, Crystal (2017) 'Influencer Extravaganza: A decade of commercial 'lifestyle' microcelebrities in Singapore' in Hjorth, Larissa, Horst, Heather et.al. (eds) Routledge Companion to Digital Ethnography, London: Routledge, pp. 158-168.

Athique, Adrian(2013) Digital Media and Society: An Introduction, Cambridge: Polity Press.

Arvidsson, Adam(2009) 'The ethical economy: Towards a Post-Capitalist Theory of Value', Capital and Class, 33(1): 13-29.

Arvidsson, Adam, Malossi, Giannino., and Naro, Serpica (2010) 'Passionate Work? Labour Conditions in the Milan Fashion Industry' Journal for Cultural Research, 14(3): 295-309.

Bolton, Kingsley (2010) 'Thank You for Calling: Asian Englishes and 'Native-like' Performance in Asian Call Centres' in Kirkpatrick, A. (ed.), The Routledge Handbook of World Englishes, London: Routledge, pp. 550-564.

Bourdieu, Pierre (1986) 'The forms of capital', in Richardson, John G. (ed), Handbook of Theory and Research for the Sociology of Education, New York: Greenwood, pp. 4658.

Errighi, Lorenza, Khatiwada, Sameer and Bodwell, Charles (2016) 'Business Process Outsourcing In The Philippines: Challenges For Decent Work',ILO Asia-Pacific Working Paper Series . Available: https://www.ilo.org/wcmsp5/groups/public/---asia/---robangkok/---sro-bangkok/documents/publication/wcms_538193.pdf, accessed 15 July 2018.

Fabros, Alinaya (2016) Outsourceable Selves: An Ethnography of Call Center Work in a Global Economy of Signs and Selves, Quezon City: Ateneo de Manila University Press.

Florida, Richard (2006) The Rise of the Creative Class: And How It's Transforming Work, Leisure, Community and Everyday Life, New York, NY: Basic Books. 
Fuchs, Christian, and Sebastian Sevignani (2013) 'What is Digital Labour? What is Digital Work? What's their Difference? And Why Do These Questions Matter For Understanding Social Media?', Triple C, 11 (2): 237-293.

Gandini, Alessandro (2016) 'The Reputation Economy' in The Reputation Economy: Understanding Knowledge Work in the Digital Society, London: Palgrave Macmillan, pp. $1-12$.

Garcia, Cathy Rose. (2014). 'How Pinoy earned P7.5-M from freelance work in just 1 year. ABS-CBN News'. Available: http://news.abs-cbn.com/business/07/27/14/howpinoy-earned-p75-m-freelance-work-just-1-year, accessed 1 August 2018.

Gill, Rosalind. and Pratt, Andy (2008) 'In the Social Factory?: Immaterial Labour, Precariousness and Cultural Work', Theory, Culture and Society, 25(7-8): 1-30.

Graham, Fiona (2010) 'Crowdsourcing Work: Labour on Demand or Digital Sweatshop?', BBC News. Available: https://www.bbc.com/news/business-11600902, accessed 1 May 2018.

Graham, M., Hjorth, Isis. and Lehdonvirta, Vili (2017) 'Digital Labour and Development: Impacts of Global Digital Labour Platforms and the Gig Economy on Worker Livelihoods', Transfer: European Review of Labour and Research, 23(2): 135162.

Graham, Mark., Lehdonvirta, V., Wood, A., Barnard, H. Hjorth, I. and D.P. Simon (2017) 'The Risks and Rewards of Online Gig Work at the Global Margins', Oxford: Oxford Internet Institute, Available :https://www.oii.ox.ac.uk/publications/gigwork.pdf, accessed 21 May 2018.

Gregg, Melissa (2011) Work’s Intimacy, Cambridge, UK: Polity Press.

Hau, Caroline S. (2017) Elites and Ilustrados in Philippine Culture, Quezon City: Ateneo de Manila University Press.

Hearn, Allison (2008) 'Insecure: Narratives and Economies of the Branded Self in Transformation Television', Continuum: Journal of Media and Cultural Studies, 22(4): 495-504.

Hearn, Alisson and Schoenhoff, Stephanie (2016) 'From Celebrity To Influencer: Tracing The Diffusion Of Celebrity Value Across The Data Stream' in Marshall, P.D., and Redmond, S.(eds) A Companion to Celebrity. Chichester: John Wiley and Sons, pp.194212. 
Hesmondhalgh, David, and Baker, Sarah (2010) 'A Very Complicated Version of Freedom: Conditions and Experiences of Creative Labour in Three Cultural Industries', Poetics, 38(1): 4-20.

Irani, Lilly (2013) 'The Cultural Work of Microwork', New Media and Society, 17(5): 720-739.

Kalleberg, Anne (2009) 'Precarious work, insecure workers: employment relations in transition', American Sociological Review, 74(1): 1-22.

Kennedy, Hellen (2011) Net Work: Ethics and Values in Web Design, Basingstoke: Palgrave Macmillan.

Khamis, Susie, Ang, Lawrence and Welling, Raymond (2016) 'Self-branding, 'microcelebrity' and the rise of social media influencers', Celebrity Studies, 8(2):1-17.

Kimura, Masataka (2003) 'The Emergence of the Middle Classes and Political Change in the Philippines', The Developing Economies, 41(2): 264-284.

Kleibert, Jana Maria (2015) 'Services-Led Economic Development: Comparing the Emergence of the Offshore Service Sector in India and the Philippines', in Lambregts, B., Beerepoot, N., and Kloosterman, R. C. (eds) The Local Impact of Globalization in South and Southeast Asia: Offshore Business Process Outsourcing in Services Industries, London and New York, NY: Routledge, pp. 29-45.

Magtibay-Ramos, Nedelyn, Estrada, Gemma Esther and Felipe, Jesus (2007) 'An Analysis of the Philippine Business Process Outsourcing Industry', Asian Development Bank, Available :https://www.adb.org/sites/default/files/publication/28359/wp093.pdf, accessed 15 July 2018.

Malefyt, Timothy and Morais, Robert (2012) Advertising and Anthropology: Ethnographic Practice and Cultural Perspectives. London: Berg.

Marwick, Alice (2015). 'You May Know Me From YouTube: (Micro)-Celebrity in Social Media' in Marshall, P.D. and Redmond, S. (eds). A Companion to Celebrity, Hoboken, NJ: John Wiley and Sons Inc.

Parreñas, Rhacel S (2015) Servants of Global Migration: Women, Migration, and Domestic Work. California: Stanford University Press.

Peck, Jaime (2005) 'Struggling with the Creative Class', International Journal of Urban and Regional Research, 29(24): 740-770.

Roberts, Sarah (2016) 'Commercial Content Moderation: Digital Labourer's Dirty Work' in Noble, S. U. and Tynes, B. M. (eds) The Intersectional Internet: Race, Sex, Class and Culture Online. New York, NY: Peter Lang. 
Rodolfo, Ceferino. (2005) 'Sustaining Philippine Advantage in Business Process Outsourcing', Philippine Institute for Development Studies, 28, Available: https://serpp.pids.gov.ph/serp-p/download.php?d=4101ands=1, accessed 1 June 2018.

Rodriguez, Robyn Magalit (2010) Migrants for Export: How the Philippine State Brokers Labour to the World. Minnesota: University of Minnesota Press

Senft, Theresa (2013) 'Microcelebrity and the Branded Self', in Harley, J. and Bruns, A. (eds) A Companion to New Media Dynamics, Wiley-Blackwell, pp.346-354.

Soriano, Cheryll Ruth and Cabanes, Jason Vincent (forthcoming). 'Digital Labour Imaginaries in the Global South' in Schofield-Clark, L., Gajjala, R. Polson, E. (eds) Routledge Companion to Media and Class. London and New York: Routledge.

Standing, Guy (2014) 'Understanding the Precariat through Labour and Work', Development and Change, 45(5): 963-980.

Van Doorn, Niels (2017) 'Platform Labour: On the Gendered and Racialized Exploitation of Low-Income Service Work in the 'On-Demand' Economy', Information, Communication and Society, 20(6): 898-914.

Wood, A. J., Graham, M. Lehdonvirta, V., Barnard, H. and Hjorth, Larissa (2016). 'Virtual Production Networks: Fixing Commodification and Disembeddedness' The Internet, Policy, and Politics Conferences, 1 (33). Available: https://ora.ox.ac.uk/objects/uuid:b17c46f0-8cb5-4e9f-bb08-18223146c23d, accessed $13^{\text {th }}$ July 2017.

Williams, Ryan (2016) The Influencer Economy: How to Launch Your Idea, Share It with the World, and Thrive in the Digital Age, Ryno Lab. 